\title{
Respuesta emocional ante estímulos afectivos en sujetos adictos a opiáceos bajo consumo controlado en el P.E.P.S.A.
}

\author{
Francisco Aguilar de Arcos'; Antonio Verdejo García²; Ángeles López Jiménez²; Matilde Montañez \\ Pareja3; Encarnación Gómez Juárez ${ }^{3}$; Francisco Arráez Sánchez ${ }^{4}$; Miguel Pérez García ${ }^{5}$
}

\author{
'Director Comunidad Terapéutica "Cortijo Buenos Aires". Granada \\ ${ }^{2}$ Becario/a Facultad de Psicología. Universidad de Granada \\ ${ }^{3}$ Psicoterapeuta Comunidad Terapéutica "Cortijo Buenos Aires". Granada \\ 4Programador informático Comunidad Terapéutica "Cortijo Buenos Aires". Granada \\ ${ }^{5}$ Profesor/a titular Facultad de Psicología. Universidad de Granada
}

Enviar correspondencia a:

Francisco Aguilar de Arcos. Centro Regional de Rehabilitación de drogodependientes "Cortijo Buenos Aires". El Fargue. 18.182 GRANADA

Tlfnos: +34 958-340225 // +34 958-340401. E-mail: aguilardearcos@yahoo.es

Recibido: Abril de 2007 Aceptado: Septiembre de 2007

\section{RESUMEN}

El objetivo de este estudio es analizar la respuesta emocional ante estímulos visuales afectivos cotidianos no relacionados con las sustancias y su consumo, en dos grupos de sujetos dependientes de opiáceos en situación de consumo prescrito y controlado (heroína y metadona vs metadona), participantes en el P.E.P.S.A. (Programa Experimental de Prescripción de eStupefacientes de Andalucía) tanto entre los dos grupos, como en cada uno de ellos en diferentes fases y también en comparación con un grupo normativo de sujetos no consumidores. Para ello, se usó el I.C.E.R.E., instrumento basado en el I.A.P.S. (International Affective Picture System) y en el S.A.M. (SelfAssessment Manikin) de Peter Lang. Los resultados muestran patrones de respuesta emocional en los sujetos consumidores de opiáceos, en relación a sujetos no consumidores, caracterizados por una menor valoración de los estímulos naturales cotidianos de naturaleza apetitiva y una mayor sensibilidad a los de naturaleza negativa y neutra, muy estables ante diferentes situaciones clínicas y de evolución en el desarrollo del P.E.P.S.A.

Palabras clave: emoción, P.E.P.S.A., drogodependientes, I.A.P.S., I.C.E.R.E.

\section{ABSTRACT}

The main objective of this study was to analyze emotional response to a set of everyday emotional visual stimuli unrelated to drug use. Two groups of prescribed opiate drug abusers (heroin+methadone vs. methadone-only groups) currently participating in the Andalusian Experimental Prescribed Drug Program ("Programa Experimental de Prescripción de eStupefacientes de Andalucía, PEPSA) were studied, and comparisons made between them, within them for different phases, and between them and a normative group of nonusers. For this purpose we used the I.C.E.R.E., an instrument based on the I.A.P.S. (International Affective Picture System) and on Peter Lang's S.A.M. (Self-Assessment Manikin). The results showed patterns of emotional response in the opiate users, compared to the non-users, characterized by a lower rating of the everyday natural stimuli of a pleasant nature and a greater sensitivity to the stimuli of a neutral and negative nature. These patterns were quite stable even in different clinical situations and stages of development of the P.E.P.S.A.

Key words: emotion, P.E.P.S.A., drug-dependent, I.A.P.S., I.C.E.R.E.

\section{INTRODUCCIÓN}

$\mathbf{U}$ no de los aspectos que la evidencia clínica nos muestra con frecuencia en el tratamiento de personas adictas a la heroína, una vez superadas las primeras etapas del mismo, es una especial falta de motivación e interés hacia todo aquello, no relacionado con la sustancia y su consumo, que en situaciones normales conforma el universo afectivo de cualquier ser humano. Por otra parte, encontramos que esta disminución de gratificación producida ante estas situaciones perdura en el tiempo y en muchos casos es definida por los propios sujetos como "vacío afectivo" o "falta de interés por todo", lo que a veces sirve de autojustificación para la recaída en el consumo.

A pesar de que aun son pocos los trabajos centrados en el estudio de estos aspectos emocionales, sobre todo ante estímulos no relacionados con la sustancia y su consumo, ha quedado claramente 
demostrado que existen alteraciones en la respuesta emocional en los sujetos drogodependientes ante estos estímulos naturales, tales como una disminución de la activación ante estímulos desagradables y ante estímulos agradables (sexuales) y una mayor percepción de control sobre la propia respuesta emocional (Aguilar, Verdejo, Peralta, Sánchez y Pérez, 2005; Gerra, Baldaro, Zaimovic, Moi, Bussandri, Raggi y Brambilla, 2003; Marques-Teixeira y Barbosa, 2005) .

Cómo estas alteraciones afectivas participan en el desarrollo y mantenimiento de un comportamiento tan aparentemente "irracional" como es la drogodependencia, ha sido hipotetizado desde recientes modelos teóricos, entre los que encontramos el propuesto por Bechara (Bechara, 2003; Bechara y Damasio, 2002: Bechara, Dolan, Denburg, Hindes, Anderson y Nathan, 2001; Bechara, Dolan y Hindes, 2002;), basado en el modelo del "marcador somático" propuesto por Damasio (Damasio, 1996). Este modelo del "marcador somático" propone que el componente emocional necesario en el proceso de toma de decisión está alterado, producto de una disfunción en la corteza ventromedial del lóbulo frontal. Esta disfunción hace que el sujeto drogodependiente no anteceda las consecuencias negativas del consumo y magnifique la "recompensa" a corto plazo del mismo, dificultando el mantenimiento de una situación de abstinencia prolongada.

Otros autores, Goldstein y Volkow (2002) proponen el modelo I-RISA (Impaired Response Inhibition and Salience Attribution), según el cual los estímulos relacionados con las sustancias y su consumo adquirirían una mayor saliencia que desplazaría la capacidad reforzadora positiva de los estímulos naturales no relacionados con dicho consumo. Dicho de otra forma, en fases avanzadas del consumo, se reduce la capacidad de la corteza prefrontal para iniciar las conductas frente a los estímulos biológicos cotidianos y para proporcionar control ejecutivo sobre la conducta de búsqueda de la droga y por otra parte, esta corteza prefrontal se vuelve más sensible a los estímulos relacionados con el consumo (Kalivas y Volkow, 2005), lo que explicaría la disminución de la activación provocada por estos estímulos afectivos cotidianos que encontramos en la clínica y ayudaría a entender de igual forma, la resistencia al mantenimiento de la abstinencia que nos encontramos frecuentemente en el ejercicio clínico.

Estos modelos promueven que existe alteración en diferentes circuitos cerebrales, provocada por la presencia de la sustancia, lo que ayuda a comprender la perdurabilidad de dichas alteraciones y la resistencia al cambio con el empleo de las técnicas terapéuticas tradicionales, centradas fundamentalmente en el abordaje de aspectos cognitivos, conductuales, sistémicos, etc.

El objetivo de este estudio es analizar la respuesta emocional, ante estímulos afectivos cotidianos no relacionados con el consumo, en sujetos adictos a la heroína en un programa de prescripción y administración controlada en el P.E.P.S.A. (Programa Experimental de Prescripción de eStupefacientes en Andalucía).

\section{Programa Experimental de Prescripción de Estupe- facientes de Andalucía (P.E.P.S.A.)}

Este es un programa promovido por la Junta de Andalucía, a través de la Dirección General para las drogodependencias y otras adicciones de la Consejería para la Igualdad y Bienestar Social y dirigido por la Escuela Andaluza de Salud Pública de la Consejería de Salud.

Se inicia en 2003 en la provincia de Granada y se define como un estudio comparativo, aleatorizado y abierto entre la prescripción diversificada de agonistas opioides apoyada en la diacetilmorfina administrada por vía intravenosa y la prescripción de metadona por vía oral, ambas en procedimientos individualizados y protocolizados, con apoyo médico-psico-social, durante nueve meses en el tratamiento de pacientes dependientes de opioides que hayan fracasado en tratamientos anteriores.

Por tanto, va dirigido a personas con un consumo de opiáceos por vía endovenosa de más de dos años de evolución, con consumo diario en los últimos 30 días, según CIE-10 (10ª revisión de la Clasificación Internacional de Enfermedades), mayores de edad, que hayan fracasado, al menos en dos ocasiones, en otras modalidades de tratamientos convencionales y que presenten al menos dos de las siguientes condiciones: Patología infecciosa asociada al consumo por vía endovenosa; trastorno mental (Puntuación mínima de 6 puntos en la escala "estado psiquiátrico" del ASI -Addiction Severity Index- o Indice de Severidad de la Adicción) o grave situación de exclusión social (puntuación mínima de 6 en las escalas "relaciones familiares/sociales" y "situación legal" del ASI). (Equipo P.E.P.S.A., 2004).

Se establecen dos grupos de sujetos, asignados aleatoriamente: A) Grupo experimental.- 31 sujetos a los que se les administran entre 100 y 500 mg. diarios de heroína intravenosa según pautas de administración individualizadas y entre 40 y 150 mg. diarios de metadona, en una dosis por vía oral. B) Grupo control.- 31 sujetos a los que les administran entre 40 y $150 \mathrm{mg}$. de metadona diarios en pauta de monodosis. 
Tabla 1.- Variables clínicas y sociodemográficas de los sujetos participantes en el estudio

\begin{tabular}{|l|c|c|c|c|}
\hline & \multicolumn{2}{|c|}{ Experimental } & \multicolumn{2}{c|}{ Control } \\
\hline & Media & D.T. & Media & D.T. \\
\hline Edad (años) & 38,26 & 5,87 & 76,33 & 5,67 \\
\hline Tiempo de consumo (años) & 19,64 & 7,44 & 19,81 & 6,65 \\
\hline Edad inicio consumo & 18,59 & 4,27 & 17,81 & 5,29 \\
\hline Edad primer tratamiento & 24,14 & 4,41 & 26,05 & 6,06 \\
\hline Tiempo con tratamiento (años) & 13,82 & 6,68 & 11,48 & 5,86 \\
\hline
\end{tabular}

(Datos cedidos por el Equipo investigador del P.E.P.S.A.)

\section{MÉTODOS}

\section{Sujetos}

41 varones consumidores habituales de opiáceos que formaban parte del programa P.E.P.S.A., participaron voluntariamente en este estudio, distribuidos en dos grupos:

- 23 de ellos formaban parte del grupo experimental a los que se les administraba heroína intravenosa y metadona vía oral.

- 18 de ellos formaban parte del grupo control, a los que se les administraba metadona por vía oral.

\section{Instrumentos}

Se usó el Instrumento Clínico de Evaluación de la Respuesta Emocional (I.C.E.R.E.) (Aguilar, Pérez y Sánchez, 2003), basado en el I.A.P.S. (International Affective Picture System) de Peter J. Lang (Lang, Öhman, y Vaitl, 1988). El I.C.E.R.E. consta de 25 imágenes agrupadas en cinco condiciones (Tabla 2). Como sistema de respuesta se utilizó el S.A.M. (Self Assessment Manikin), sistema diseñado por Lang (Hodes, Cook y Lang, 1985; Lang, 1980), que permite, mediante muñecos que lo hace más intuitivo, recoger las respuestas de los sujetos sobre la experiencia emocional percibida, ante cada fotografía presentada, en las tres dimensiones emocionales: Valencia, Activación y Dominancia. En este estudio, se utilizó su versión de lápiz y papel.

Las 25 imágenes utilizadas en el I.C.E.R.E. corresponden a los siguientes números del I.A.P.S.: 9181, 6230, 7009, 1460, 7233, 6020, 8600, 4664, 2630, $4659,9040,3010,6010,3080,1811,1440,4232$, 4531, 9340, 3010, 7224, 4608, 4210, 2352 у 2205.
Tabla 2.- Descripción de las 5 condiciones de las imágenes

\begin{tabular}{|c|c|c|c|}
\hline & VALENCIA & ACTIVACIÓN & DOMINANCIA \\
\hline Condición 1 & Neutra & Calmada & Neutra \\
\hline Condición 2 & Desagradable & Neutra & Baja \\
\hline Condición 3 & Agradable & Neutra & Alta \\
\hline Condición 4 & Desagradable & Activante & Baja \\
\hline Condición 5 & Agradable & Activante & Alta \\
\hline
\end{tabular}

\section{Procedimiento}

A todos los sujetos se les explicó el objetivo del estudio, se les instruyó suficientemente en la utilización del I.C.E.R.E. y del S.A.M. y se les pidió un consentimiento voluntario de participación en el estudio.

El I.C.E.R.E. se presentó a los participantes de la siguiente forma:

a) A los sujetos experimentales:

$1^{\text {a }}$. En los tres primeros meses de iniciar el ensayo y siempre en los 30 minutos previos a la inyección intravenosa de heroína.

$2^{a}$.- En los últimos tres meses del ensayo, una vez en los 30 minutos previos a la inyección intravenosa de heroína y otra ocasión en los 30 minutos posteriores a la inyección intravenosa de la heroína, con un intervalo, entre una y otra de estas presentaciones entre 15 y 20 días para cada sujeto, aleatorizando el orden.

b) A los sujetos controles:

$1^{a}$.- En los tres primeros meses de iniciar el ensayo y siempre en los 30 minutos previos a la administración oral de metadona.

$2^{a}$.- En los últimos tres meses del ensayo y siempre en los 30 minutos previos a la administración oral de metadona. 


\section{Variables}

Variables Independientes

Como variables independientes se utilizaron la variable pertenencia al grupo de sujetos, manipulado entre grupos, en el primer análisis a tres niveles: pertenencia al grupo experimental vs. al grupo control vs. al grupo de sujetos normativos (los valores del grupo normativo proceden de la estandarización realizada por Moltó et al., 1999 y Vila et al., 2001) y en el segundo análisis a dos niveles: grupo experimental vs. grupo control ; la variable condición (condición de cada diapositiva, manipulada entre grupos, a cinco niveles (tabla 2) y la variable momento de la presentación de la prueba para los sujetos participantes manipulado intrasujeto:

- Grupo experimental.- A tres niveles: a) En los tres primeros meses de iniciar el P.E.P.S.A. y en los 30 minutos previos a la inyección intravenosa de heroína; b) en los tres últimos meses de iniciar el P.E.P.S.A. y en los 30 minutos previos a la inyección intravenosa de heroína; c) en los tres últimos meses del P.E.P.S.A. y en los 30 minutos posteriores a la inyección intravenosa de heroína.

- Grupo control.- A dos niveles: a) En los tres primeros meses de iniciar el P.E.P.S.A. y en los 30 minutos previos a la administración oral de metadona; b) en los tres últimos meses del P.E.P.S.A. y en los 30 minutos previos a la administración oral de metadona.

\section{Variables Dependientes}

Como variables dependientes se usaron la media aritmética de las puntuaciones obtenidas mediante el S.A.M. para cada una de las 25 imágenes y en cada una de las tres dimensiones afectivas (valencia, activación y dominancia).

\section{Análisis estadísticos}

Se realizó un MANOVA bifactorial, siendo un factor la comparación entre los diversos grupos: experimental vs. control vs. sujetos normativos (para los grupos control y experimental se analizaron los valores obtenidos en la presentación realizada en el momento previo a la administración oral de metadona y a la administración intravenosa de heroína respectivamente, en la fase inicial del P.E.P.S.A) y el otro la condición a la que pertenecía la imagen. Esto nos permitía conocer si las posibles diferencias entre los grupos cambiaban según el tipo de imagen que se presentaba (efecto de la interacción). En esta ocasión las manipulaciones de las variables independientes se realizaron entre grupos.
Para comprobar si existían diferencias entre el grupo control y el experimental en las fase inicial y final del P.E.P.S.A. en los momentos previos a la administración de la metadona y de la heroína respectivamente, se realizaron 3 ANOVAS de medidas repetidas, uno para cada dimensión afectiva (valencia, activación y dominancia), en un modelo mixto, siendo un factor la fase del P.E.P.S.A en la que tenía lugar la administración de la prueba (tres primeros meses y tres últimos meses del P.E.P.S.A.), manipulado intrasujeto y el otro la pertenencia a uno de los dos grupos manipulado entregrupo.

Para comprobar si existían diferencias entre el grupo experimental en el momento inmediatamente previo y el inmediatamente posterior a la administración intravenosa de heroína, se realizaron 3 ANOVAS de medidas repetidas, uno para cada dimensión afectiva (valencia, activación y dominancia) en un modelo mixto, siendo un factor el momento de la presentación de la prueba al grupo experimental manipulado intrasujeto y el otro, la condición a la que pertenecía cada imagen. En este caso la manipulación fue entregrupo.

\section{RESULTADOS}

Comparación de la respuesta ante estímulos emocionales entre los sujetos pertenecientes al grupo normativo respecto al grupo control y al grupo experimental al inicio del P.E.P.S.A.

En primer lugar, se estudió si existían diferencias estadísticamente significativas entre el grupo control y el experimental, con respecto a los valores del grupo normativo, en la respuesta al S.A.M. ante la exposición a las imágenes en las tres dimensiones afectivas (valencia, activación y dominancia), realizando un MANOVA bifactorial, siendo un factor la pertenencia a cada grupo (control vs experimental vs normativo), y el otro factor la condición de las imágenes (condiciones 1 a 5), ambos factores manipulados entre grupos. Las variables dependientes fueron la media aritmética de las puntuaciones de cada grupo obtenidas mediante el S.A.M. para cada una de las 25 imágenes en las tres dimensiones afectivas (valencia, activación y dominancia). Los resultados mostraron que existían diferencias estadísticamente significativas en la interacción entre los dos factores, grupo y condición experimental [Lambda de Wilks = 0 ,129; F (24, $168.819)=7,233 ; p<0,001]$, aunque dicha interacción sólo era significativa para las variables dependientes valencia $[F(8,60)=2,221$; $p<0.039]$ (figura 1) y activación $[F(8,60)=19,111 ; p<0.001]$ (figura 2). Para la variable dependiente dominancia la interacción se encontraba próxima a la significación estadística [F(8, $60)=2,004 ; p<0.062$ ] (figura 3). 


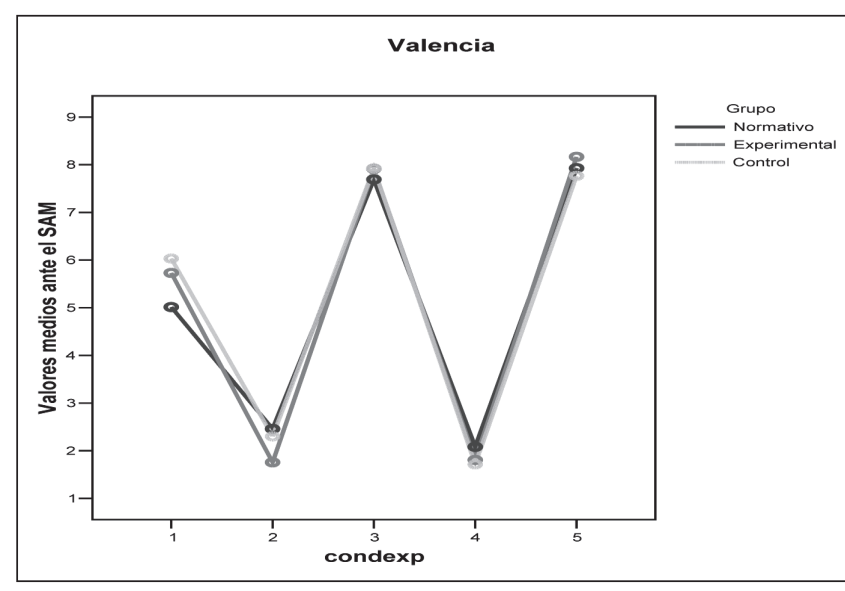

Figura 1.- Comparación de las puntuaciones obtenidas en el S.A.M. para los grupos normativos, experimental y control, en las 5 condiciones experimentales de la dimensión afectiva Valencia.

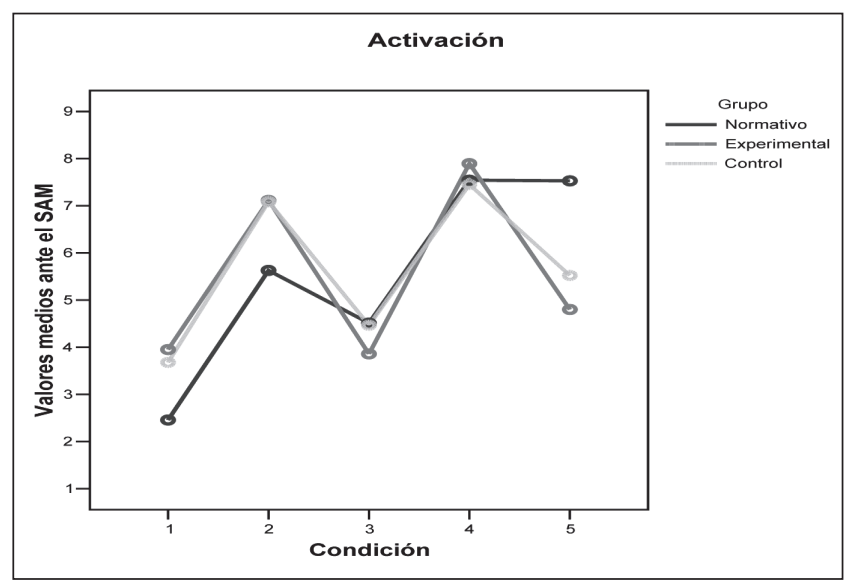

Figura 2.- Comparación de las puntuaciones obtenidas en el S.A.M. para los grupos normativos, experimental y control, en las 5 condiciones experimentales de la dimensión afectiva Activación.

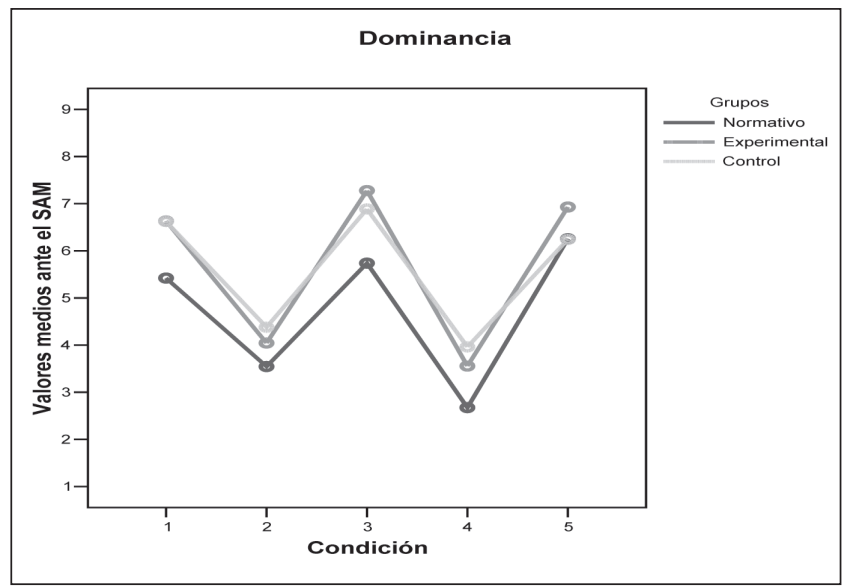

Figura 3.- Comparación de las puntuaciones obtenidas en el S.A.M. para los grupos normativos, experimental y control, en las 5 condiciones experimentales de la dimensión afectiva Dominancia.
El análisis de la interacción en la variable dependiente valencia se centró en estudiar las posibles diferencias entre los tres grupos en las 5 condiciones de las diapositivas. Para ello, se realizaron 5 ANOVAS unifactoriales, uno para cada condición, utilizando como variable independiente la pertenencia a cada grupo (experimental vs. control vs. sujetos normativos), y siendo la variable dependiente la media aritmética de las puntuaciones de cada grupo obtenidas mediante el S.A.M. para cada una de las 25 imágenes en la dimensión valencia. Los resultados mostraron que no existían diferencias estadísticamente significativas en ninguna de las cinco condiciones.

También se realizó el análisis de la interacción en la variable dependiente activación estudiando las posibles diferencias entre los tres grupos en las 5 condiciones de las diapositivas. Para ello, se realizaron 5 ANOVAS unifactoriales, uno para cada condición, utilizando como variable independiente la pertenencia a cada grupo (control vs. experimental vs. normativos), y siendo la variable dependiente la media aritmética de las puntuaciones de cada grupo obtenidas mediante el S.A.M. para cada una de las 25 imágenes en la dimensión activación. Los resultados mostraron que existían diferencias estadísticamente significativas en la Condición $1[F(2,12)=18,434 ; p<0.001]$, en la Condición $2[F(2,12)=9,124 ; p<0.005]$, en la Condición 3 $[F(2,12)=6,638 ; p<0.042]$ y en la Condición $5[F(2$, 12) $=37,362 ; p<0.001$ ] (tabla 3 ).

El análisis a posteriori, usando el test de Bonferroni, para la condición 1 mostró que existían diferencias estadísticamente significativas entre el grupo normativo y el control $(p<0.003)$, siendo la puntuación del primero menor que la del segundo y también entre el grupo normativo y el experimental $(p<0.001)$, siendo la puntuación del primero menor que la del segundo. Para la condición 2 el test de Bonferroni mostró que existían diferencias estadísticamente significativas entre el grupo normativo y el grupo control $(p<0.011)$, siendo el primero menor que el segundo y también entre el grupo normativo y el experimental $(p<0.010)$ siendo el primero menor que el segundo. Para la condición 3 , se mostró que las diferencias estadísticamente significativas se daban entre el grupo normativo y el experimental $(p<0.021)$, siendo el primero mayor que el segundo y también entre el grupo control y el experimental $(p<0.032)$, siendo el primero mayor que el segundo. Por último, para la condición 5 el análisis a posteriori determinó que existían diferencias estadísticamente significativas entre el grupo normativo y el control $(p<0.001)$, siendo el primero mayor que el segundo y también entre el grupo normativo y el experimental $(p<0.001)$, siendo también el primero mayor que el segundo. (Tabla 3) 
Tabla 3.- Descripción de los resultados obtenidos mediante el S.A.M.ante la presentación de las imágenes de contenido sexual, para cada uno de los grupos de sujetos estudiados en cada una de las dimensiones afectivas y los análisis post-hoc

\begin{tabular}{|c|c|c|c|c|}
\hline $\begin{array}{c}\text { Dimensión } \\
\text { emocional }\end{array}$ & Condición & Interacción & \multicolumn{2}{|c|}{ Bonferroni } \\
\hline $\begin{array}{c}\text { Valencia } \\
{[F(8,60)=2,221 ; p<0.039]}\end{array}$ & & & & \\
\hline & 1 & 0.001 & 0.003 & Nor<Con \\
& 2 & & 0.001 & Nor $<$ Exp \\
& & 0.005 & 0.011 & Nor<Con \\
Activación & 3 & 0.042 & 0.010 & Nor $<$ Exp \\
{$[F(8,60)=19,111 ; p<0.001]$} & & & 0.021 & Nor $>\operatorname{Exp}$ \\
& 5 & 0.001 & 0.032 & Con>Exp \\
& & & 0.001 & Nor $>$ Con \\
& & & & Nor $>\operatorname{Exp}$ \\
\hline
\end{tabular}

Nor = Grupo normativo; Con = Grupo control (metadona); Exp = Grupo experimental (heroína).

Comparación de la respuesta ante estímulos emocionales de los sujetos pertenecientes al grupo control $y$ al experimental entre el inicio $y$ el final deI P.E.P.S.A.

En segundo lugar, se estudió si la administración de metadona vía oral y de heroína vía intravenosa durante el desarrollo del P.E.P.S.A. provocaba diferencias estadísticamente significativas en el grupo control y experimental, tanto entre ellos, como en cada uno de ellos a lo largo del ensayo, en la respuesta al S.A.M. ante la exposición a las imágenes. Para ello, se realizaron 3 ANOVAS de medidas repetidas, uno para cada dimensión afectiva (valencia, activación y dominancia), en un modelo mixto, siendo un factor la fase del P.E.P.S.A en la que tenía lugar la administración de la prueba (tres primeros meses y tres últimos meses del P.E.P.S.A.), manipulado intrasujeto y el otro la pertenencia a uno de los dos grupos manipulado entregrupo. Los resultados mostraron que existían diferencias estadísticamente significativas en la interacción entre los dos factores, grupo fase del P.E.P.S.A. para la variable dependiente activación [F(1, 48) = 4,337; $p<0.044]$.

El análisis de la interacción en la variable dependiente activación se centró en estudiar las posibles diferencias entre los dos grupos en las dos fases del P.E.P.S.A. y en las 5 condiciones de las diapositivas. Para ello, se realizaron 5 ANOVAS unifactoriales, uno para cada condición, utilizando como variable independiente la pertenencia a cada grupo (control vs. experimental), y siendo la variable dependiente la media aritmética de las puntuaciones de cada grupo obtenidas mediante el S.A.M. para cada una de las 25 imágenes en la dimensión activación. Los resultados mostraron que no existían diferencias estadísticamente significativas en ninguna de las cinco condiciones.

Comparación de la respuesta ante estímulos emocionales de los sujetos pertenecientes al grupo experimental en la fase final del P.E.P.S.A. entre el momento inmediatamente previo e inmediatamente posterior a la administración intravenosa de la heroína.

En tercer lugar, se estudió si la respuesta ante estímulos emocionales se modificaba en función de la diferente situación clínica atribuible a los diferentes niveles de heroína en sangre, provocando diferencias estadísticamente significativas en el grupo experimental en la respuesta al S.A.M. ante la exposición a las imágenes. Para ello, se realizaron tres ANOVAs de medidas repetidas, siendo el factor 1 el momento en que se realizó la prueba con respecto a la administración de la dosis de heroína, manipuladas intrasujeto (Previo a la administración vs. posterior a la administración), y como factor 2 la condición de las imágenes, manipuladas entre grupos (condiciones 1 a 5). Las variables dependientes fueron la media aritmética de las puntuaciones de cada presentación obtenidas mediante el S.A.M. para cada una de las 25 imágenes en las tres dimensiones afectivas (valencia, acti- 
vación y dominancia). Los resultados mostraron que no existían diferencias estadísticamente significativas en la interacción entre los dos factores, grupo y condición experimental [Lambda de Wilks $=0,766 ; \mathrm{F}$ (12, 100.830)=0,892; $p<0,558]$.

\section{DISCUSIÓN}

Los resultados obtenidos nos muestran que existen diferencias en la forma de respuesta al S.A.M. ante estímulos emocionales entre los sujetos consumidores de opiáceos (heroína y metadona) y los no consumidores, en la línea de lo ya encontrado en estudios anteriores (Aguilar et al, 2005); que la administración de metadona vía oral y de heroína intravenosa durante el P.E.P.S.A. durante un periodo no inferior a seis meses, provoca pocas diferencias estadísticamente significativas entre el grupo control y experimental en la respuesta al S.A.M. ante la exposición a las imágenes y por último, que no existen diferencias estadísticamente significativas en la respuesta ante estímulos emocionales en el grupo experimental del P.E.P.S.A., en función de la diferente situación clínica atribuible a los diferentes niveles de heroína en sangre, al comparar esta respuesta, en el grupo experimental, en los momentos inmediatamente previos y posteriores a la administración intravenosa de heroína.

Centrándonos en los resultados obtenidos en el primer análisis en relación con el grupo experimental del P.E.P.S.A., vemos que este grupo presenta unos niveles de activación subjetiva menor en condiciones de valencia agradable (condiciones 3 y 5) que las obtenidas por el grupo normativo. Esto va en la línea de lo propuesto por autores como Goldstein y Volkow (2002) en su modelo I-RISA (Impaired Response Inhibition and Salience Attribution) (Alteración de la Inhibición de Respuesta y de la Atribución de Relevancia), según el cual los estímulos apetitivos cotidianos pierden capacidad estimular a favor de los estímulos relacionados con el consumo. Sin embargo ante estímulos de valencia desagradable, (condiciones 2 y 4) el nivel de activación subjetiva es igual o superior a los sujetos del grupo normativo. Esto es consistente con los resultados obtenidos en estudios sobre consumidores de heroína, donde se encuentra un incremento de la sensibilidad al dolor (Bie, 2005) y a las contingencias de castigo de tareas cognitivas en los sujetos en programas de mantenimiento con metadona (Ersche, Roiser, Clark, London, Robbins y Sahakian, 2005).

También se da este aumento en el nivel de activación subjetiva de los sujetos consumidores de opiáceos en la condición 1 (estímulos de valencia neutra) en la línea de lo planteado por Gerra et al (2003) quienes encuentran una mayor reactividad fisiológica y respuesta subjetiva en los sujetos drogodependientes ante estos estímulos neutros.

Todo esto nos hace hipotetizar que el consumo prolongado de heroína no produce una disminución generalizada de la capacidad de respuesta emocional ante estímulos afectivos cotidianos, sino que esta disminución es selectiva hacia aquellos de naturaleza apetitiva. Esto ayudaría a entender lo que en la clínica se presenta como sensación de "vacío" ante los estímulos afectivos naturales, tales como familia, sexo, pareja, amigos, etc., que relatan los sujetos drogodependientes y que en múltiples ocasiones argumentan como una causa que facilita la recaída en el consumo.

Resultados similares obtenemos en el primer análisis para los sujetos del grupo control del P.E.P.S.A. en relación al grupo normativo, salvo en la condición 3 en que los valores de activación subjetiva obtenidos por el grupo control no difieren estadísticamente del grupo normativo y sí son superiores a los obtenidos por el grupo experimental, por lo que sustancialmente encontramos que los resultados son similares entre los grupos experimental y control del P.E.P.S.A.. Dichos resultados van en línea con lo encontrado en estudios previos, donde existe semejanza en los cambios producidos en la respuesta emocional entre consumidores de sustancias cuyo efecto clínico principal es sedante, y diferente a los producidos en consumidores de sustancias cuyo efecto principal es excitante. (Aguilar et al, 2005)

Por tanto, el patrón diferencial de los consumidores activos de heroína y metadona participantes en el P.E.P.S.A., con respecto a los sujetos normativos, se caracteriza sustancialmente por un incremento de la experiencia subjetiva de activación en respuesta a estímulos neutros y desagradables, y una reducción de esta experiencia subjetiva de activación en respuesta a estímulos muy agradables.

En lo referente al segundo análisis, no se encuentran diferencias estadísticamente significativas al analizar los resultados por condición, lo que indica, primero que la respuesta emocional ante estímulos afectivos visuales entre los sujetos del grupo control y experimental del P.E.P.S.A. es semejante al inicio del programa, lo que coincide con una adecuada aleatorización de la muestra. Segundo, que la administración de heroína intravenosa y metadona vía oral o sólo metadona vía oral, administradas de forma controlada, durante un periodo no inferior a seis meses no genera diferencias importantes en la respuesta emocional. Esta ausencia de diferencias significativas entre estos grupos puede deberse a que a ambos se les administra metadona o también a que ambos han sido consumidores de heroína, de larga evolución, en el periodo anterior a su participación en el P.E.PS.A. y que los cambios en la respuesta emocional provocados por dicho consumo son poco sensibles a los cambios en 
la situación clínica, social, familiar, etc, producidos durante su participación en el ensayo clínico. Estos resultados nos presentarían así una estabilidad en el tiempo de las alteraciones de la respuesta emocional en sujetos consumidores de opiáceos.

Podríamos hipotetizar que una vez que los cambios en el patrón de respuesta ante estímulos emocionales se instaura, dichos cambios son poco sensibles a los cambios producidos en las condiciones biopsicosociales del sujeto, al menos mientras el consumo de la sustancia permanece. De acuerdo con el modelo I-RISA (Goldstein y Volkow, 2002) esto facilitaría su persistencia en la adicción y da importancia a los factores emocionales en el proceso adictivo.

En cuanto a los resultados obtenidos en el tercer análisis, donde se comparan la respuesta ante estímulos emocionales de los sujetos pertenecientes al grupo experimental en la fase final del P.E.P.S.A., entre el momento inmediatamente previo e inmediatamente posterior a la administración intravenosa de la heroína, encontramos que no existen diferencias significativas en las respuestas ante los estímulos afectivos, a pesar de encontrarnos ante dos situaciones clínicas bien diferenciadas, la inmediatamente previa a la administración de la dosis de heroína, caracterizada por un estado de agitación, malestar y de inminencia en el deseo de recibir la dosis de heroína, propio de la situación de abstinencia a la sustancia, frente a la inmediatamente posterior a dicha administración, donde predomina la sedación.

Esta estabilidad de los resultados obtenidos hace pensar que una vez instaurados estos patrones de respuesta emocional provocados por el consumo de heroína, son resistentes y poco sensibles a los niveles plasmáticos de la sustancia, lo que ayuda a explicar lo encontrado en la práctica clínica, es decir, que el mantenimiento de la adicción a la heroína, no la podemos basar exclusivamente en la necesidad de consumir para evitar el estado negativo provocado por la abstinencia a la misma.

En resumen, encontramos patrones de respuesta emocional en los sujetos consumidores de opiáceos, en relación a sujetos no consumidores, caracterizados por una menor valoración de los estímulos naturales cotidianos de naturaleza apetitiva y una mayor sensibilidad a los de naturaleza negativa y neutra, con una estabilidad poco sensible a los cambios de naturaleza biopsicosocial generados en el sujeto drogodependiente. Estos resultados nos ayudan a entender la resistencia a abandonar una situación de consumo y a dar mayor importancia al factor emocional en el fenómeno adictivo, ante la dificultad de disfrutar de los eventos afectivos cotidianos que constituyen la vida emocional de un sujeto. De aquí, la necesidad de avanzar en el estudio de nuevas formas de intervención, dirigidas a devolver la sensibilidad hacia esos estímulos afectivos cotidianos e incorporarlos en los programas terapéuticos.

Es necesario reconocer las limitaciones que este estudio presenta, al no poder contar con sujetos en los que el consumo de otras sustancias ajenas a las estudiadas esté totalmente controlado, a pesar de que la administración, tanto de heroína como de metadona, estuviera perfectamente supervisada por el equipo investigador del P.E.P.S.A. al tratarse de un ensayo clínico. Esta circunstancia puede añadir variables extrañas que puedan dificultar la interpretación de los resultados, aunque es lícito añadir que este policonsumo es una característica que define a este grupo de población y, por tanto, a su realidad clínica.

\section{AGRADECIMIENTOS:}

Al Equipo P.E.P.S.A. (Dirección General para las drogodependencias y otras adicciones de la Consejería para la Igualdad y Bienestar Social y Escuela Andaluza de Salud Pública de la Consejería de Salud de la Junta de Andalucía).

\section{REFERENCIAS}

Aguilar, F., Pérez, M. y Sánchez, M. B. (2003). Evaluación emocional en drogodependencias. Sevilla: Junta de Andalucía. Consejería de Asuntos Sociales. Comisionado para las Drogodependencias.

Aguilar, F., Verdejo, A., Peralta, M. I., Sánchez, M. B., y Pérez, M. (2005). Experience of emotions in substance abuser exponed to images containing neutral, positive and negative affective stimuli. Drug and Alcohol Dependence, 30, 89-101.

Bechara, A. (2003). Risky business: Emotion, decisionmaking and addiction. Journal of Gambling Studies, 19, 23-51.

Bechara, A. y Damasio, H. (2002). Decision-making and addiction (part I): Impaired activation of somatic states in substance dependent individuals when pondering decisions with negative future consequences. Neuropsychologia, 40, 1675-1689.

Bechara, A., Dolan, S., Denburg, N., Hindes, A., Anderson, S.W. y Nathan, P.E. (2001). Decision-making deficits, linked to a dysfunctional ventromedial prefrontal cortex, revealed in alcohol and stimulant abusers. Neuropsychologia, 39, 376-389.

Bechara, A., Dolan, S. y Hindes, A. (2002). Decisiónmaking and addiction (part II): Miopia for the future or hypersensitivity to reward?. Neuropsychologia, 40, 1690-1705. 
Bie, B. (2005). cAMP-mediated mechanisms for pain sensitization during opioid withdrawal. Journal of Neuroscience: The Official Journal Of The Society For Neuroscience, 25, 3824-3832.

Damasio A. R.,(1996). The somatic marker hypothesis and the possible functions of the prefrontal cortex. Philosophical Transactions of the Royal Society of London. Series B, Biological Sciences, 351, 1413-1420.

Equipo P.E.P.S.A. (2004). Programa experimental de prescripción de estupefacientes en Andalucía (PEPSA). Adicciones, 16, 22-24.

Ersche, K. D., Roiser, J. P., Clark, L., London, M., Robbins, T. W. y Sahakian, B. J. (2005). Punishment induces risky decision-making in methadone-maintained opiate users but not in heroin users or healthy volunteers. Neuropsychopharmacology, 30, 2115-2124

Gerra, G., Baldaro, B., Zaimovic, A., Moi, G., Bussandri, M., Raggi, M. A. et al (2003). Neuroendocrine responses to experimentally-induced emotions among abstinent opioid-dependent subjects. Drug and Alcohol Dependence, 71, 25-35.

Goldstein R. Z. y Volkow N. D. (2002). Drug addiction and its underlying neurobiological basis: Neuroimaging evidence for the involvement of the frontal cortex. American Journal of Psychiatry, 159, 1642-1652.

Hodes, R. L., Cook, F. W. y Lang, P. J. (1985). Individual differences in autonomic response: Conditioned association or conditioned fear? Psychophysiology, 22, 545-560.

Kalivas, P. W. y Volkow, N. D. (2005). The neural basis of addiction: a pathology of motivation and choice. American Journal of Psychiatry, 162, 1403-1413.

Lang, P. J. (1980). Behavioral treatment and bio-behavioral assessment: Computer applications. En J. B. Sidowski, J. H. Johnson y T. A. Willians (Eds.), Technology in Mental Healt Care Delivery System (pp. 119-137). Norwood, N.J.: Ablex.

Lang, P. J., Öhman, A. y Vaitl, D. (1988). The International Affective Picture System (Photografic slides). Gainesville, FL: University of Florida, Center for Research in Phychophisiology.

Marques-Teixeira, J. E. y Barbosa, M. F. S. (2005). Emotional states and informational brain processing in drug addicts free of drugs: An ERPs study. International Journal of Psychiatry in Clinical Practice, 9, 213-220.

Moltó, J., Montañés, S., Poy, R., Segarra, P., Pastor, M. C., Tormo, M. P. et al. (1999). Un nuevo método para el estudio experimental de las emociones: El International Affective Picture System (I.A.P.S.), adaptación española. Revista de Psicología General y Aplicada, 52, 55-87.

Vila, J., Sánchez, M., Ramírez, I., Fernández, M. C., Cobos, P., Rodríguez, S., et al. (2001). El Sistema Internacional de Imágenes Afectivas (IAPS): Adaptación española. Segunda parte. Revista de Psicología General y Aplicada, 54, 635-657. 
